PAPER

\title{
'He who helps the guilty, shares the crime'? INGOs, moral narcissism and complicity in wrongdoing
}

\author{
Pete Buth, ${ }_{1}^{1}$ Benoit de Gryse, ${ }^{2}$ Sean Healy, ${ }^{2}$ Vincent Hoedt, ${ }^{2}$ Tara Newell, ${ }^{2}$ \\ Giovanni Pintaldi, ${ }^{3}$ Hernan del Valle, ${ }^{2}$ Julian C Sheather, ${ }^{4}$ Sidney Wong ${ }^{2}$
}

\begin{abstract}
- Additional material is published online only. To view, please visit the journal online (http://dx.doi.org/10.1136/ medethics-2017-104399).

1 Medecins Sans Frontieres, Boston, Massachusetts, USA ${ }^{2}$ Medecins Sans Frontieres, Amsterdam, The Netherlands ${ }^{3}$ Medecins Sans Frontieres, Rome, Italy ${ }^{4}$ British Medical Association, London, UK
\end{abstract}

\section{Correspondence to} Dr Julian C Sheather, British Medical Association, London SW179PX, UK:

jsheather@bma.org.uk

Received 29 May 2017 Revised 6 November 2017 Accepted 5 February 2018

Published Online First

17 March 2018
Check for updates

To cite: Buth $\mathrm{P}$, de Gryse $B$ Healy $S$, et al. J Med Ethics 2018:44:299-304.

\section{ABSTRACT}

Humanitarian organisations often work alongside those responsible for serious wrongdoing. In these circumstances, accusations of moral complicity are sometimes levelled at decision makers. These accusations can carry a strong if unfocused moral charge and are frequently the source of significant moral unease. In this paper, we explore the meaning and usefulness of complicity and its relation to moral accountability. We also examine the impact of concerns about complicity on the motivation of humanitarian staff and the risk that complicity may lead to a retreat into moral narcissism. Moral narcissism is the possibility that where humanitarian actors inadvertently become implicated in wrongdoing, they may focus more on their image as self-consciously good actors than on the interests of potential beneficiaries. Moral narcissism can be triggered where accusations of complicity are made and can slew decision making. We look at three interventions by Médecins Sans Frontières that gave rise to questions of complicity. We question its decision-guiding usefulness. Drawing on recent thought, we suggest that complicity can helpfully draw attention to the presence of moral conflict and to the way International Non-Governmental Organisations (INGOs) can be drawn into unintentional wrongdoing. We acknowledge the moral challenge that complicity presents to humanitarian staff but argue that complicity does not help INGOs make tough decisions in morally compromising situations as to whether they should continue with an intervention or pull out.

\section{INTRODUCTION}

Humanitarian organisations often work alongside those responsible for serious wrongdoing. In these circumstances, accusations of moral complicity are sometimes levelled at decision makers. These accusations can carry a strong if unfocused moral charge and are frequently the source of significant moral unease. In this paper, we explore the meaning and usefulness of complicity and its relation to moral accountability. We also examine the impact of concerns about complicity on the motivation of humanitarian staff and the risk that complicity may lead to a retreat into moral narcissism. Moral narcissism is the possibility that where humanitarian actors inadvertently become implicated in wrongdoing, they may focus more on their image as self-consciously good actors than on the interests of potential beneficiaries. Moral narcissism can be triggered where accusations of complicity are made and can slew decision making. We look at three interventions by Médecins Sans Frontières (MSF) that gave rise to questions of complicity. We question its decision-guiding usefulness. Drawing on recent thought, we suggest that complicity can helpfully draw attention to the presence of moral conflict and to the way International Non-Governmental Organisations (INGOs) can be drawn into unintentional wrongdoing. We acknowledge the moral challenge that complicity presents to humanitarian staff but argue that complicity does not help INGOs make tough decisions in morally compromising situations as to whether they should continue with an intervention or pull out.

\section{COMPLICITY AND 'STAY OR GO' QUESTIONS}

Debates around complicity can be fraught for INGOs because they arise in situations where the complicit action or omission is taken in pursuit of a substantive good-and any chance of that good being realised will be lost if the complicit act, or omission, is foregone. The wrongs arising from the complicit action are in tension with the goods arising from it.

It is worth setting out how arguments from complicity are usually constructed. The argument is typically of the following kind. A principal agent, such as a state, is directly involved in wrongdoing. A second agent, such as an INGO, intervenes, ordinarily to assist those subject to the principal agent's wrongdoing. Despite the intentions of the INGO, and their ordinary prudential actions aimed at delivering benefits, they make some causal contribution to the principal agent's wrongdoing. A typical example is where an INGO's humanitarian resources are co-opted by an armed agent. The INGO starts helping the guilty.

Ordinarily, those who make accusations of complicity seek to do several things. First, they identify that the INGO is-inadvertently-making a causal contribution to wrongdoing: in the scenario above it is the INGO's resources that contribute. Second, because of the causal contribution, they ascribe some degree of moral responsibility to the complicit agent-they are at least partly guilty of the crime and their actions therefore fall under moral judgement; and finally, the charge of complicity is usually presumed sufficient, by itself, for the INGO to withdraw. Arguments based in complicity are frequently regarded as moral trump cards. In the discussion that follows, it is with step 2 and particularly step 3 that we are concerned.

\section{WHAT DO WE MEAN BY COMPLICITY?}

Complicity emerges from 'accomplice'. Legally, it refers to joint enterprise or common purpose: 
an accomplice shares the goals, and the intentions-the mens rea-of the primary perpetrator. In this sense, accusations of complicity levelled at INGOs are absurd. It is difficult to take seriously the idea that INGOs share the intentions of the perpetrators of wrongdoing-ordinarily the wrongdoing that triggered the INGO's intervention. We set this version of complicity aside.

More recently, a more nuanced understanding of complicity has emerged. Lepora and Goodin describe a sliding scale of degrees of complicity, with joint enterprise at one end and a far more attenuated connection to wrongdoing at the otherso attenuated that decision makers may have little or no idea their choices are contributing to the wrongdoing of others. ${ }^{1}$ In between, they identify a range of what they call complicity's 'conceptual cousins'. These include conspiracy, co-operation, collusion, connivance, condoning, consorting and contiguity. They divide this cluster of concepts into three groups: acts involving coprincipals or joint wrongdoing; acts involving contributors, whether intentional or not and those acts, such as connivance, which involve non-contributors, such as physical proximity or 'contiguity'.

Among these conceptual cousins, the focus of our concern are those acts involving contributors. These acts causally contribute to the wrongdoing of others, 'without ... in any way constituting part of that principal wrongdoing. ${ }^{2}$

There are many strengths to Lepora and Goodin's analysis. They recognise the moral messiness of the contexts in which INGO's work. They also recognise the enormous variation-and the enormously various moral shades-of inadvertent wrongdoing by INGOs. They identify that INGOs can be involved in harms they neither intend nor foresee and recognise that complicity is sometimes used lazily, as a catch-all term, when what is at a stake is a more nuanced range of moral concerns. They also recognise that complicity may be morally required. They argue that Oskar Schindler's complicity with the Nazi's was justified by the good he could do in keeping large numbers of Jewish people from transportation and death. ${ }^{3}$

Problems arise with Lepora and Goodin's ascription of moral responsibility for acts involving contributors. In extending the reach of complicity and its conceptual cousins, they risk overextending the scope of moral responsibility. At times, Lepora and Goodin promote a familiar account of moral responsibility involving voluntariness, intention and knowledge of likely outcomes. ${ }^{4}$ At others, they ascribe moral responsibility to decisions that contribute to the wrongdoing of others in ways the contributor did not intend, had no control over and could not possibly foresee. As French argues, this takes us outside any plausibly defensible idea of moral responsibility and accountability for actions. In doing so, they can make INGOs seem worse than they are and risk a retreat into moral narcissism, with associated problems for decision making. ${ }^{5}$

\section{COMPLICITY AND MORAL RESPONSIBILITY}

As we have seen, accusations of complicity carry a strong charge-have a particularly bad moral odour-and are sometimes presented as trump cards over stay or go decisions. The reasons for this are not transparent and it is worth asking why it might be so. One straightforward (consequentialist) reason may be that complicity suggests that instead of doing good, INGOs are doing harm and should desist. The difficulty is that complicit decisions are seldom of this straightforward kind. Good and bad outcomes are often inextricably linked: the good of the intervention cannot be achieved without the bad. Nor do concerns about complicity seem directly linked to overall sums of good and illthe charge of complicity does not seem to rest on crudely consequentialist concerns. Another possibility, one that may account for some of the psychological charge of complicity, is that proximity to wrongdoers leads to feelings of compromise and contamination: guilt by association. This is a close ally of what Lepora and Goodin call 'contiguity'. They highlight two possible sources of wrongness here. The first has to do with character: contiguity should repulse a good person and to remain in close proximity is to raise concerns about character. The second is that those who remain close to wrongdoing are more likely to end up contributing to it. (Interestingly, Lepora and Goodin identify an important problem for INGOs when they recognise that contiguity can at times be interpreted as implicit approval. Many INGOs ask themselves whether their presence by itself can add legitimacy to a regime perpetrating wrongdoing, and therefore unwillingly contribute to it. $)^{6}$ Another plausible contribution to the malodour attached to complicity is its capacity to confuse the scope of individual moral responsibility-that some responsibility for the most serious wrongdoing is transferred to humanitarian agents. We now turn to questions of moral responsibility.

We have seen that a complicit action is one in which a secondary agent, the complicitor, makes a causal contribution to a wrongdoing perpetrated by another. As Peter French has convincingly demonstrated, causal contribution is not, by itself, sufficient to accrue moral responsibility. ${ }^{5}$ A simple example makes this clear. Consider an INGO deciding whether to provide significant humanitarian aid to a large population displaced into a neighbouring country by war. Following a needs and risk assessment, the INGO decides at a specific time (Tx) to commit significant resources. Sometime later (Ty), a warlord invades the neighbouring country and makes off with those resources, thus enhancing his ability to wage the war that displaced the population. Although at (Ty) the INGO has now made a causal contribution to the conflict, it is absurd to suggest that an ordinarily prudent INGO was morally responsible at (Tx). Causal contribution is not synonymous with moral responsibility.

More importantly for our purposes, if the INGO makes a similar decision at (Ty), knowing that there is now a significant likelihood that its resources might be confiscated for nefarious purposes, the scope of its moral accountability shifts. A decision made knowing that there is a reasonable likelihood that it will causally contribute to wrongdoing does accrue some moral responsibility. This is probably closer to reality for most INGOs when making decisions in circumstances that give rise to accusations of complicity. Several questions remain though: how much moral responsibility, and for what?

Without wanting to enter a long discussion concerning the conditions for ascribing moral responsibility, it is reasonable to suggest that someone who kills, and someone who makes an unintended causal contribution to that killing are not equally morally responsible. The one who intends and carries out the killing is guilty of the crime. At (Ty), our INGO does not take on responsibility for the waging of the war, or anything like it. It neither intends nor perpetrates the primary wrongdoing. But given that it is within the scope of the INGO's agency to pull its resources, and cease to contribute, it seems fair to ascribe some form of moral responsibility. But for what? If, at (Ty), the INGO decided to continue contributing, but the warlord is deposed and peace ensues, the INGO is no longer contributing and ceases to be complicit. As French argues, there is no plausible way that the INGO, as a complicitor, can predict an outcome that it neither intends nor works towards- the outcome is too contingent on other actors. What it must accept, if it continues 
to supply resources, is responsibility for a decision at (Ty) that involved a risk that its resources would be co-opted: a lesser evil by some degree. Given that these decisions are ordinarily made in pursuit of some other good, moral responsibility for the principal wrongdoing seems more attenuated still.

When thinking about complicity in relation to inadvertent wrongdoing by INGOs, as a first step we need to distinguish those consequences for which moral responsibility can reasonably be imputed to the INGO. As more information about unintended consequences emerges, our moral responsibility can change. If, despite our best intentions, we have a reasonable belief that our decisions will have undesirable consequences, then they will fall to some degree within the scope of our moral accountability. Our retrospective assessment at (Ty) of our decision at ( $\mathrm{Tx})$, is different to our assessment of likely prospective moral responsibility for the consequences of the decision we make at (Ty). We do not however take moral responsibility for the primary wrongdoing that remains with the perpetrator.

\section{MOTIVATION, HUMANITARIAN AGENTS AND MORAL NARCISSISM}

The fact that we may have some moral responsibility for the ills arising from our contribution to another's wrongdoingthat we are complicit-does not bring our decision making to a close. It is not decisive. As Lepora and Goodin make clear, in some circumstances the complicit decision may, as in the case of Schindler, be morally preferable. There will be times when we decide that, despite an action being complicit, it may, nonetheless, based on an 'all things considered' judgement, be the right or necessary choice. Questions of complicity give way to a familiar-although by no means easy-decision-making process, whereby the overall balance of good and ill, based on an assessment of all morally relevant reasons, will need to be made. It is at this point-where we are involved in the difficult decision as to whether to stay or go in morally compromising circumstancesthat moral narcissism can threaten judgement.

The academic literature on moral narcissism is not extensive, nor are we aware of its use in academic reflection on humanitarian engagement. Kundnani, writing in a foreign policy context, describes it as "the tendency to think about morality in terms of how your actions make you feel about yourself rather than in terms of their consequences for others". ${ }^{7}$ More recently, it has been used to criticise American liberals who regard moral goodness as being dependent on the content of their beliefs rather than the consequences of their choices. ${ }^{8}$ From our perspective, moral narcissism refers to the tendency of some humanitarian actors to think more in terms of how their actions are perceived, and their image as a 'good' person or agent, than the effect of their actions. The fear of being perceived as morally contaminated involves the risk that humanitarian actors will withdraw from circumstances in which they could, on balance, do far more good than harm. Concerns about the moral self-image of the individual or organisation can usurp the benefits that could be provided to those in dire need.

Although the phrase moral narcissism is-deliberately-pejorative, it emerges from a problem first identified by Bernard Williams in his critique of consequentialism-what is sometimes called the integrity objection. Consequentialism is the straightforward view that an act is only right or wrong in so far as its consequences are right or wrong. And a consequence is right or wrong dependent on whether it increases or reduces overall utility, well-being or happiness. It follows therefore that, to be a good person, we are under a moral injunction to live in such a way as to maximise good consequences. Although the consequences for the agent matter morally, they count no more than the consequences for all other individuals whose well-being is affected by the decision. As good consequentialists, we are under an injunction to step out of our own perspective and view the world objectively, 'from the viewpoint of the universe'. Our decisions should be in accordance with what, from this perspective, will lead to the highest overall satisfaction. Williams' main objection is that this misconceives what we are like as moral agents:

The point is that (the agent) is identified with his actions as flowing from projects or attitudes which... he takes seriously at the deepest level, as what his life is about... It is absurd to demand of such a man, when the sums come in from the utility network which the projects of others have in part determined, that he should just step aside from his own project and decision and acknowledge the decision which utilitarian calculation requires. ${ }^{9}$

For Williams, moral agents have good reasons to seek to realise their (good) personal projects and, at times, their commitment to these projects will be in tension with the demands of utility. There can be something incompatible between the demands of personal integrity-our virtuous desire to realise our self in the world-and the demands of consequentialism.

Some humanitarians, faced with a conflict between a strongly felt personal injunction of a 'do no harm' type, and a decision based on utilitarian calculus that would involve them in identifiable wrongdoing, may understandably seek to prioritise the former. Some may also be troubled by the presence of conflicting-and possibly incommensurable-moral reasons, both of which seem to have a claim on them and that cannot be reconciled by reference to an external standard.

Although we are wary of generalising about motives, it is plausible to suggest that humanitarian work attracts (some of) those strongly motivated to do good and who are therefore likely to be particularly troubled by conflicts of these kinds. We recognise the importance of these issues, and in what follows, do not wish to trivialise them. We seek instead to identify a problem for INGOs arising from these contradictory demands. Williams recognises the difficulty. What happens, he asks, where an agent 'is forced with a reliable choice between a detestable action and an outcome which will be utilitarianly worse? ${ }^{10}$ And if I decline the detestable action, am I "open to the charge of being concerned with (my) own integrity or purity or virtue at others' expense" ? ${ }^{11}$ Am I guilty of what Williams calls moral self-indulgence? Barry and Fried make a similar point. In criticising the Kantian injunction to refrain from lying, even where lying could save someone's life, Barry and Fried suggest that maintaining personal integrity in such a context 'becomes a form of narcissism'. ${ }^{12}$

The point at which an appropriate concern for one's own moral integrity turns into moral self-indulgence or narcissism is not easy to identify. For Williams, it arrives when motivation shifts-assuming the agent is not a thoroughgoing moral narcissist and no shift is possible-from concern for the interests of others to concern for the preservation of the agent's self-image. ${ }^{13}$ It is initially tempting to see this as cousin to an issue in political philosophy, what Michael Walzer has termed the problem of 'dirty hands'. Put simply, this involves the question of whether political leaders might be called on to violate deep moral prohibitions to bring enormous benefits-or avoid catastrophic harms - to their communities. ${ }^{14}$ Does the pursuit of some great, even overwhelming good justify malicious means? 
Fortunately, few INGOs, and fewer of their staff, face questions on this scale. Dirty hands problems also involve deliberate, eyes-wide-open wrongdoing, whereas complicity here involves non-intended causal contributions to wrongdoing. Rubenstein has recently introduced the helpful concept of 'spattered hands' ${ }^{15}$ Considering 'stay or go' type questions, Rubenstein argues that complicity is unhelpful, running the risk that it will 'characterise INGO's intentions as worse than they are', lead INGOs to 'commit sins of omission (ie, to withdraw)' and also lead to 'unhelpful defensiveness on the part of aid practitioners'. ${ }^{16}$ Complicity, she argues, should be replaced by the clear-eyed, if rueful acknowledgement that INGOs may get drawn into wrongdoing, and that this may be necessary to achieve the goods at which they aim. Accusations of complicity, and fears that their hands may be spattered by the wrongdoing of others, may precipitate an unhelpful retreat into moral narcissism and deflect the proper objects of INGOs concern away from beneficiaries towards self-image.

\section{COMPLICITY IN CONTEXT: MYANMAR, LIBYA AND 'THE BERM' REFUGEE CAMP ON THE SYRIA-JORDAN BORDER}

In this section, we look at three humanitarian interventions that gave rise to concerns about complicity. Although complicity was not determinative in decision making, and was not the only moral issue engaged, we identify where accusations of complicity arose and examine how useful they were in decision making. These decisions were challenging and controversial. Reasonable people took opposing views. The purpose of this section is not to explore the full range of moral questions that arose but to look at those that gave rise to questions of complicity.

\section{Myanmar}

MSF has been working in Myanmar for nearly 20 years. Initially, the intention was to work with the Rohingya, a minority Muslim population being brutally suppressed by the majority Buddhists. As access to Rakhine state, where the Rohingya were being accommodated, was difficult, the provision of HIV treatment was started in several states as a 'foot-in-the-door'. Over time, the HIV treatment increased significantly, involving up to 35000 patients. In 2014, following a flare up of violence in northern Rakhine, MSF treated dozens of wounded patients. The government criticised MSF and asked it to leave Rakhine. The question was whether MSF should suspend activities in Rakhine-and cease bearing witness_as a price for maintaining its presence elsewhere in Myanmar. MSF decided that it would maintain its presence in Myanmar even if forced to suspend activities in Rakhine.

Complicity was claimed in two ways:

- By refusing to speak out about conditions in Rakhine, whatever the cost to its overall presence in Myanmar, MSF was helping to facilitate the violence-silence involved complicity in the killings.

- By continuing to provide aid in other states, MSF was lending legitimacy to the government and indirectly enabling the violence to continue.

It is worth looking in a little more detail at how the charge of complicity developed. The requirement to speak out in support of wronged groups is strongly felt in MSF. It is sometimes referred to as the obligation to bear witness-usually referred to in the French as temoignage. Bearing witness involves proximity and identification with those suffering, and the obligation to speak out on their behalf. For some in MSF, remaining silent with an eye to possible consequences raised a problem of the shape that Williams identified: the utilitarian calculus seemed to override the deeply held requirements of conscience. It is likely that the sharpest accusations of complicity arose out of this clash of moral reasons.

Let us accept that the decision not to speak out may have causally contributed to the wrongdoing-had MSF spoken out, the regime might have changed tack. Let us also accept that the decision was made knowing there was a risk that not speaking out would have this consequence and some moral responsibility accrues to MSF-not responsibility for the killing of the Rohingya, but responsibility for making a decision that may have failed to constrain those perpetrating the wrongdoing. This is the case from complicity. The difficulty though is that the Myanmar government had imposed significant costs on speaking out. There were the interests of those tens of thousands of patients to whom MSF was providing HIV/AIDS support. With no other actor to take over, a decision resulting in eviction from Myanmar would significantly harm them. Having provided services for 15 years, MSF had strong enduring obligations to those populations and speaking out, given the reasonable risk that it would result in being asked to leave the country, would be a grave decision.

How much moral work is complicity doing here? It identifies that failing to speak out makes a certain-negative-causal contribution to another's wrongdoing. In this case, because there was some knowledge of this possible contribution, some moral responsibility falls to MSF. But it has not helped MSF make the overall decision. In doing this, it must take into consideration the potential impact of speaking out on those being supported by its HIV programme. Although those who saw an absolute requirement to speak out may have felt their principles were surrendered to a consequentialist logic, those who supported a tactical silence also argued that, irrespective of consequences, MSF had a duty to those patients with HIV it was supporting. It looks like a choice between, on the one hand, a decision that makes a causal contribution to another's wrongdoing-a complicit decisionand one that avoids complicity but may both lead to serious harms and breach a long-standing duty of care.

There is a risk here that complicity inappropriately loads the moral dice and gives rise to a possibility of moral narcissism. An agent concerned about her personal integrity may, when faced with such a decision, say, as Williams puts it: "if others are going to bring evil and injustice into the world it will not be by my agency that it comes about". ${ }^{17}$ Such a statement may straightforwardly be made by individuals, but it may also, plausibly, be made by organisations-we are an agent of good, we will not bring evil into the world, we will not contribute to the oppression of the Rohingya and if we must leave Myanmar it is not our decision but the decision of the government.

Perhaps the best that can be said here is that, for MSF, many competing moral concerns were in play. The consequences of their actions will always be morally important. But the consequences are notoriously difficult to assess, and they do not exhaust the moral interests involved. There are conflicting duties here: the duty to bear witness to the suffering of the Rohingya was in tension with established duties to a large population of patients with HIV. What weight to give to the competing duties, and how, in turn to assess the moral weight of uncertain consequences? This was the decision that was thrust on MSF.

\section{Libyan detention centres: how close to horror is too close?}

Refugees fleeing conflict, famine and poverty in Chad, Nigeria, Sudan, Eritrea and Somalia frequently cross into Libya in the hope of finding a better life or seeking further transit across the Mediterranean into Europe. ${ }^{18}$ Often in poor mental and physical 
health, having trekked thousands of miles through desert, they are rounded up by government troops or local militia and held in formal or informal detention centres. While detained they can be subject to beatings and torture and other forms of abuse including the deliberate withholding of food, water, access to latrines and fresh air. They are also targets for violent extortion.

MSF has made vigorous efforts to reach them. To do so, it has formed relationships with those running the detention centres. This involves working alongside people-traffickers and those perpetrating serious and sustained abuse. MSF staff have reported strong feelings of compromise and moral contamination. Although seeking a balance between the need to gain access to suffering people while avoiding being too closely identified with the regime is a challenge for most humanitarian organisations, providing support in camps whose primary purpose seems to be the exploitation of inmates has led to concerns about complicity-that they are contributing to the maintenance of the camps. In addition, where inmates have been given medical care following torture or violent extortion and their health has improved, this has meant they are more likely to be further tortured or beaten. Is the provision of healthcare complicit in the further abuse?

Practically speaking, it can be difficult in relation to the first question to establish a causal contribution: how likely is it that, absent MSF's involvement, the camps will cease to function? In the second question, it may be possible to gather evidence that a recovery in health will lead to further torture or beating. Although the question of causal contribution will always be central to decision making, and in practice can be difficult to assess, let us accept that in this instance we have identified some causal contribution. We know we are making an unintended contribution to the wrongdoing of others, and we know we must take some moral responsibility. Again though, beyond identifying possible causal contribution and, to an extent, the scope of moral responsibility, it is hard to see what complicity adds to our overall decision making. We are still left with a decision to make-whether, despite a degree of complicity, we should continue with the intervention. And here the overall balance of good and ill looks like a better guide to decision making than complicity. We know that some harm will come of the good that is intended: those working here will never be invulnerable to the charge of complicity. But the question is whether, in these morally compromising situations, the good outweighs the ill.

As an aside, it is probably worth mentioning that when answering this question there is one source of information that must not be overlooked: the views of the inmates. Not everyone who is in extremis loses the ability to decide where their interests lie. In some cases, people may have very strong views. Any decision about whether to stay or go must involve discussion with those directly affected by the choice, in this case the inmates themselves.

\section{Refugees on the Syrian-Jordanian border}

MSF was seeking to provide medical aid to a large refugee population, probably $>90000$ people, stranded in a demilitarised zone, known as 'the berm', between Jordan and Syria. The majority were Syrian refugees. In June 2016, Jordan closed its borders with Syria after an IS suicide attack on the Rukban military base. The establishment of a permanent camp in the berm supported the Jordanian desire to prevent more refugees entering from Syria. The US supported the Jordanian position. At the time Jordan was home to some 650000 refugees and was reluctant to accept more, partly on security grounds. In seeking long-term solutions to the crisis, the USA, the EU and, according to some reports, the United Nations Office for the Co-ordination of Humanitarian Affairs, were discussing whether they should push the refugees back from the berm and into a 'safe zone' inside Syria. ${ }^{19}$

After the border closure, Jordan blocked the delivery of most humanitarian aid and radically altered the mechanisms for delivering water and food. The population was extremely vulnerable, both in terms of health needs, and from the proximity of military factions. The berm was not an established refugee camp. Its inhabitants were seeking refuge in Jordan and beyond, but with the border closed, it had become a large and informal holding place almost completely lacking the infrastructure, goods and services to maintain a large displaced population.

MSF was asked to provide services close to the Syrian side of the border to allow the Jordanians to move the refugees back into Syria and to access MSF services. The Syrians made it clear that they did not wish to move, but the Jordanians were threatening to shut off the water supply and reopen it in the designated area. If MSF started working in the new location, its services, alongside the water supply, could operate as a coercive 'pull' factor, with MSF arguably being co-opted into serving the political goals of the Jordanians, goals it regarded as seriously destructive of the refugees' interests.

The extreme humanitarian needs of the population were clear, but while seeking to provide support, MSF also identified potential negative consequences giving rise to accusations of complicity. These included:

- MSF's involvement in the berm conferred legitimacy on it, risking it becoming a permanent camp and preventing occupants moving into Jordan: a political 'capture' of MSF's mission promoting the Jordanian desire for a 'closed border' against Syrian refugees. Opening facilities in the proposed new location inside the Syrian border would similarly support Jordanian political goals.

- By working in the berm and failing to speak out about abuses to continue supplying medical aid, MSF assisted or facilitated those abuses.

As a large, well-resourced and relatively powerful INGO, with the ability to offer emergency humanitarian support to large numbers of people, MSF's missions are liable to political capture and to accusations of facilitating or assisting in geopolitical power play. But how useful to MSF in terms of its decision making is the concept of complicity when faced with political machinations on this scale?

As with the fore-running cases, we can reasonably set aside the question of MSF being an accomplice. Only a paranoid interpretation of the actions of INGOs would have them directly sharing the intentions of the major political actors. The more important question is whether, but for MSFs-and other INGOs-intervention, a better outcome would result? Was MSF getting in the way of a better outcome?

It is worth looking at the choice in more detail. On the one hand is the 'complicit' choice-to go on providing essential medical and humanitarian services to a desperately needy population despite the risk of nefarious political capture and causal contribution to an outcome not in the interests of the refugees it is seeking to assist.

On the other is withdrawal. From one perspective, withdrawal could be a simple washing of hands-we will not be the agent by which wrong comes into the world. From another it can be thought of as a strategic decision to help facilitate a longterm solution more beneficial for refugees. But if MSF decides to withdraw its services because, in effect, they are a 'sticking plaster', then it is relying on the possibility that a short-term 
intensification of pain and suffering will mean an alternative solution must be found.

And here INGOs should pause. In places like Syria, long-term political outcomes are almost impossibly difficult to predict, whereas immediate suffering is both tangible and, to some degree, remediable. Any humanitarian organisation effectively trading short-term remediable suffering for speculative political gains will attract moral criticism. Serious and immediate harms should be weighted heavier than speculative and uncertain future gains.

So again, beyond identifying the possibility of causal contribution to another's wrongdoing, and inviting speculation on the scope of an INGOs moral responsibility, it is not clear how much complicity adds to the stay or go decision in play here.

\section{CONCLUSION}

Humanitarian INGOs work in some of the most difficult places in the world. The good they seek to do can be captured by other actors and used to facilitate wrongdoing. This has given rise to concerns about complicity: that INGOs participate or help bring about the ills they are trying to remedy and are therefore worthy of moral censure. In this paper, we have looked at three humanitarian missions where questions of complicity have been raised. We have seen that complicity draws attention to the possibility that INGOs can causally contribute to wrongdoing. Nevertheless, complicity is subject to wide interpretation, is often used loosely and can give rise to moral disorientation and decisional paralysis. Although complicity is sometimes used as a moral trump card, we have also suggested that it does not in fact offer much to guide decision making in relation to stay or go questions. It lacks specificity, can make INGOs seem much worse than they are and can also sow doubt about the scope of moral responsibility among humanitarian workers, paralysing decision making and giving rise to psychological distress and, at times, precipitating a retreat into moral narcissism.

Although complicity can point to situations in which INGOs make a causal contribution to wrongdoing, this is only a first step. After the extent of the causal contribution has been identified-and therefore, in prospect, the likely scale of an INGOs moral responsibility has been established-a further decision is usually required. This will ordinarily involve an all-things-considered assessment of the likely benefits and harms of any intervention. Like complicity, such an assessment will consider motivation, and it will take into consideration the acts and intentions of others, the scope of the INGO's ability to influence outcomes, and critically, with the needs and considered opinions of possible beneficiaries sharply in focus, the extent to which the good it seeks to realise justifies the harms into which it is unavoidably drawn. It is important to recognise that in complex situations acts, however well-intended, can have terrible consequences. Intentions by themselves are not sufficient and there is no excuse for moral-or political-naivety. What is needed is a clear-eyed, careful and politically informed assessment of each mission.
Contributors JCS has been the principal author and editor. He has taken case studies, examples and commentary and suggestions from the other authors and edited and adapted the manuscript over time. PB has provided detailed editorial comment, reflected on the case studies and made conceptual suggestions in relation to the structure of the paper. BdG has provided detailed editorial and drafting commentary and was one of the lead authors in relation to the material on Myanmar. SH provided detail commentary in relation both to the Jordanian berm and Myanmar. He provided detailed editorial commentary on the conceptual material and the paper's structure. VH was instrumental in developing some of the conceptual material relating to complicity in the specific humanitarian context. He made extensive contributions on both the case studies and the conceptual material. TN made specific contributions to the case studies and made extensive editorial suggestions, which were incorporated during several of the paper's earlier drafts. GP made extensive comments and suggestions on all versions of the manuscript. $\mathrm{HdV}$ provided extensive comments on all stages of the manuscript production. SW worked closely with the primary author in conceiving the scope and focus of the paper, provided detailed comments on the case studies and conceptual material and was involved in extensive discussion with the other MSF authors throughout the development of the paper.

Competing interests None declared.

Provenance and peer review Not commissioned; externally peer reviewed.

(c) Article author(s) (or their employer(s) unless otherwise stated in the text of the article) 2018. All rights reserved. No commercial use is permitted unless otherwise expressly granted.

\section{REFERENCES}

1 Lepora C, Goodin R. On complicity \& compromise. 8. Oxford: Oxford University Press, 2015.

2 Lepora C, Goodin R. On complicity \& compromise. 41. Oxford: Oxford University Press, 2015.

3 Lepora C, Goodin R. On complicity \& compromise. 158. Oxford: Oxford University Press, 2015.

4 Lepora C, Goodin R. On Complicity \& Compromise. 96. Oxford: Oxford University Press, 2015.

5 French PA. Complicity: that moral monster, troubling matters. Crim Law Philos 2016;10:575-89

6 Lepora C, Goodin R. On complicity \& compromise. 51. Oxford: Oxford University Press, 2015

7 Kundnani H. Moral narcissism. Weblog. 2010 https://hanskundnani.com/2010/12/17/ moral-narcissism/ (accessed 24 Sep 2017).

8 Simon RL. Moral Narcissism. Commentary. 2016 https://www. commentarymagazine.com/articles/moral-narcissism-least-great-generation/ (accessed 24 Sep 2017).

9 Stanford Encyclopedia of Philosophy. Bernard Williams. https://plato.stanford.edu/ entries/williams-bernard/ (accessed 27 Sep 2017).

10 Williams B. Utilitarianism and moral self-indulgence. In: Moral Luck. 42. Cambridge: CUP, 1981.

11 Williams B. Utilitarianism and moral self-indulgence. In: Moral Luck. 44. Cambridge: CUP, 1981.

12 Barry B, Fried C. And Who Is My Neighbor? Yale Law J 1979;88:629-58.

13 Williams B. Utilitarianism and moral self-indulgence. In: Moral Luck. 45. Cambridge: CUP, 1981

14 Stanford Encyclopedia of Philosophy. The Problem of Dirty Hands. https://plato. stanford.edu/entries/dirty-hands/ (accessed 2 Oct 2017).

15 Rubenstein JC. Between samaritans and states: the political ethics of humanitarian NGOS. OUP: Oxford, 2015.

16 Rubenstein JC. Between samaritans and states: the political ethics of humanitarian NGOs. 98. Oxford: OUP, 2015.

17 Williams B. Utilitarianism and moral self-indulgence. In: Moral Luck. 50. Cambridge: CUP, 1981.

18 Kingsley P. Dramatic photos show refugees fleeing Libya being rescued at sea. The Guardian. 2016 https://www.theguardian.com/world/2016/aug/29/dramatic-photosshow-refugees-fleeing-libya-being-rescued-at-sea (accessed 1 Oct 2016).

19 'Take the People out; let aid in' Undated Frontieres Medecins SansUnpublished internal briefing paper. 